\title{
Proposta de um Jogo lúdico sobre a temática resíduos sólidos: uma amaeaça a biodiversidade e conservação do Rio Bocaina
}

\author{
Motion for a Ludic game on the theme of solid waste: a threat to \\ biodiversity and conservation of Bocaina river
}

\author{
1 Ana Paula Gomes de Souza anapaulagomesdesouza@ig.com.br \\ 1 Henrique Amaral Reis \\ 1 Isaias Gomide Monteiro \\ 2 Denise Celeste G. de A. Rodrigues \\ 2 Rosana A. Ravaglia Soares \\ 2 Ronaldo Figueiró Portela Pereira
}

1 Mestrandos no curso de Ensino em Ciências da Saúde e Meio Ambiente - UniFOA.

2 Mestrandos no curso de Ensino em Ciências da Saúde e Meio Ambiente - UniFOA.

\section{RESUMO}

Os recursos hídricos do Brasil são um dos maiores do mundo; entretanto, atualmente o país passa por uma grande crise hídrica. Além dos problemas causados pelo reduzido índice de água nos reservatórios e mananciais, o descarte inadequado de resíduos sólidos tem se tornado um agravante, provocando impactos ambientais no ar, água, solo e nas espécies existentes ao redor. Portanto, o gerenciamento de resíduos tem se tornado um grande desafio. Formar sujeitos conscientes e capazes de transformar o seu meio, são metas a serem buscadas. Surge então a necessidade de produzir, de maneira lúdica a alunos do Ensino Fundamental, um jogo educativo que aborde os impactos ambientais causados pelo descarte incorreto de resíduos sólidos. 0 aluno precisa estar interligado ao conhecimento e o professor necessita direcionar métodos eficazes de ensino. Portanto, a promoção de determinadas práticas em sala de aula possibilita a interação dialógica e auxilia no processo ensino-aprendizagem.

\section{PALAVRAS-CHAVE}

Resíduos sólidos; Biodiversidade; Rio Bocaina; Jogo educativo.

\begin{abstract}
Brazil has one of the largest water resources in the world; currently, however, the country is undergoing a major water crisis. In addition to problems caused by the low water level in reservoirs and fountains, the improper disposal of solid waste has been aggravated, provoking environmental impact on air, water, soil and other existing species in surrounding areas. As a result, waste management has become a major challenge in the country. Developing conscious individuals who are able to transform their environment is a goal to pursue. There is also the need to come up with a playful teaching and learning approach aimed at elementary school students, such as an educational game that addresses the environmental impacts caused by improper disposal of solid waste. The students must be connected to information and knowledge, and the teacher needs to propose effective teaching methods. Consequently, the promotion of certain practices in the classroom enables the dialogic interaction and aids in the teaching-learning process.
\end{abstract}

\section{KEYWORDS}

Solid waste; Biodiversity; Bocaina River; Educational game.

\section{Como você deve citar?}

SOUZA, Ana Paula Gomes de et al. Proposta de um Jogo lúdico sobre a temática resíduos sólidos: uma amaeaça a biodiversidade e conservação do Rio Bocaina. Cadernos UniFOA, Volta Redonda, n. 29, p. 15-20, dez. 2015. 


\title{
1 INTRODUÇÃO
}

Um dos maiores recursos hídricos do mundo está presente no Brasil. Toda essa riqueza está espalhada em diversas regiões do país e pode ser encontrada em águas subterrâneas, rios superficiais, lagos e lagoas que formam ecossistemas surpreendentes e ricos em biodiversidade (SILVA,2016).

Atualmente, o Brasil atravessa uma das maiores crises hídricas de sua história, com significativa redução do volume de água em todas as regiões do país. Essa redução altera a dinâmica dos ecossistemas, impacta, direta ou indiretamente, a vida dos seres vivos que neles habitam, e influencia toda a economia do país, como lembra Silva (2016).

Além da significativa redução da quantidade de água aos seres vivos, com a consequentemente redução do espaço do habitat e proporcional redução na oferta de alimento aos seres vivos que habitam esses ecossistemas, ocorre o agravamento da situação com o despejo e acúmulo de poluentes causados pelo chorume ${ }^{3}$ infiltrados e lixiviados que contaminam as águas.

\begin{abstract}
O principal destino dos resíduos é o LIXÃO, um local a céu aberto onde o lixo é disposto de qualquer maneira e sem tratamento, o que acaba causando inúmeros problemas ambientais, pela falta de atendimento às normas de controle. O local analisado apresenta inúmeros riscos, como a poluição das águas subterrâneas e cursos d'água vizinhos, proliferação de animais parasitas e odores de fermentação. Em consequência, ocasiona a produção de chorume[1] (AMORIM et al, 2010, p. 163).
\end{abstract}

No município de Barra Mansa, por muitos anos, funcionou às margens do rio Bocaina o antigo vazadouro de lixo da cidade (PANÇARDES, 2012, p. 5), situado na Rodovia RJ-157. Esse vazadouro não dispunha de qualquer intervenção que viesse evitar a contaminação das águas do rio Bocaina, das águas subterrâneas e também do solo, já que o chorume apresenta "substâncias altamente solúveis [...] que pode contaminar as águas do subsolo e superficiais" (IPT, 2000 apud MORAES, 2014, p. 34) por meio da percolação.

Com a inauguração do Centro de Tratamento de Resíduos - CTR/Barra Mansa, em 20 de abril de 2012, esse vazadouro foi desativado e passou a ser monitorado pelo CTR/Barra Mansa, que realizou algumas intervenções a fim de mitigar essas contaminações. Apesar de todo o maciço ter sido coberto com terra e em seu entorno ter sido construído um sistema de canaletas que coletam e armazenam o chorume, transportando-o a uma lagoa para posterior transporte e tratamento, essas intervenções podem não ser suficientes para se evitar a contaminação do solo e das águas subterrâneas e, principalmente, das águas do rio. Ainda seria possível que essas águas continuem a ser contaminadas através da percolação do chorume, já que o rio está situado ao lado do vazadouro, o que compromete a biodiversidade e a conservação do ecossistema formado por esse rio.

Além de causar impacto visual desagradável, o acúmulo de resíduos também provoca alterações negativas no ambiente, na saúde das populações próximas, perdas econômicas e degradação paisagística. 0 aumento de resíduos pode, por exemplo, favorecer o desenvolvimento de microrganismos patogênicos como bactérias e fungos; doenças diversas como hepatite, micose e tétano; ser responsável pelo baixo rendimento na atividade pesqueira, além de destruir a flora e fauna local (ARAÚJO \&COSTA, 2003).

\footnotetext{
30 chorume é um líquido escuro gerado pela degradação dos resíduos que contém altas concentrações de metais pesados, bactérias e matéria orgânica. Nos lixões, o chorume é responsável pela contaminação do solo, lençóis subterrâneos e cursos d'água. Ao cair na água, ele necessita de grande quantidade de oxigênio para se decompor, o que pode ser fatal à fauna aquática, que morre por asfixia. A presença do chorume em águas subterrâneas pode ter consequências extremamente sérias para o meio ambiente e para a saúde pública por apresentar compostos altamente tóxicos. O chorume é bem mais agressivo que o esgoto e precisa de um tratamento adequado (http://planetaterranet.blogspot.com.br/2009/11/chorume.html).
} 
Embora o lixão da cidade tenha sido desativado e suas consequências ambientais mitigadas, os desgastes ambientais causados por ele perduram por muitos anos:

Nos lixões existe uma série de impactos ambientais, ocasionados pela perda da qualidade do meio ambiente (água, ar, solo), pela produção dos seres que habitam nas proximidades e, visivelmente, impactos na estética do local onde está inserido (AMORIM et al., 2010, p. 168).

Desta forma, a desativação e mitigação das consequências ambientais não resolvem os impactos ambientais causados pelo mesmo porque:

Quanto a desativação dos aterros sanitários é realizada por prefeituras e empresas particulares, só é exigida e/ou realizada a cobertura das células de deposição do lixo com solo e o plantio de alguma espécie vegetal. A problemática paisagística do local é resolvida, mas não há o controle e o monitoramento dos passivos ambientais e do meio ambiente no entorno do aterro. Assim, o gás metano gerado na decomposição do lixo escapa sem controle para a atmosfera, contribuindo, desta forma, para o aquecimento global; e a percolação do chorume através do solo pode contaminá-lo, além de atingir as águas superficiais e subterrâneas, transportando metais potencialmente tóxicos e substâncias orgânicas diversas (MORAES, 2014 p. 36).

Assim, o objetivo deste trabalho é propor uma atividade lúdica que possa facilitar a compreensão dos alunos do $6^{\circ}$ ano do Ensino Fundamental sobre os impactos ambientais decorrentes da contaminação das águas pelo chorume produzidos pelos resíduos, bem como conhecer os tratamentos adequados para os diversos resíduos que preservam e conservam o meio ambiente e sua biodiversidade.

Acredita-se que a realização deste trabalho e a possível utilização do jogo educativo possam facilitar a compreensão dos alunos quanto ao manejo dos resíduos, produzidos diariamente por eles, além de possibilitar a reflexão e mudança de atitude quanto à destinação final dos mesmos.

De acordo com Gomes et al. (2001), "o jogo pedagógico ou didático é aquele fabricado com o objetivo de proporcionar determinadas aprendizagens, diferenciando-se do material pedagógico, por conter o aspecto lúdicoe utilizado para atingir determinados objetivos pedagógicos".

\section{MÉTODOS E TÉCNICAS}

O presente trabalho constitui uma proposta de atividade que utiliza algumas abordagens metodológicas (a ludicidade, o trabalho em campo e a interação prática com os elementos de estudo) para atingir os objetivos de conscientização e sensibilização dos alunos para com as questões de poluição e contaminação dos ecossistemas causados pelo acúmulo inadequado de resíduos. Eles estão relacionados à preservação de recursos hídricos, em especial as águas do Rio Bocaina. Nossa meta é abordar a problemática da questão de forma interativa e lúdica, a fim de tornar mais facilmente compreensível aos estudantes do ensino fundamental todo o processo de degradação ambiental ocasionado pelo despejo inadequado de resíduos às margens de rios, lagoas, mananciais e todas as áreas ligadas a rede hídrica, incluindo atividades industriais e de origem doméstica.

Primeiramente, torna-se necessária a construção de uma base teórica de conhecimentos, com a qual se procura tornar mais viável aos estudantes elaborarem uma compreensão coerente acerca do tema de estudo proposto.

Assim, em sala, os alunos receberão conhecimentos e informações relacionadas aos recursos hídricos da região e como a degradação gerada pelo despejo inadequado de resíduos poderá afetar os ecossistemas. Esta atividade deverá ocorrer logo antes de se realizarem as planejadas atividades em campo. 
Posteriormente, aulas práticas em campo poderão ser realizadas de modo a auxiliar na compreensão do conteúdo. Tais aulas consistirão, por exemplo, em uma visitação guiada aos locais onde poderão ser observados na prática os efeitos dos resíduos nos ecossistemas, em especial nos rios, e também ser demonstradas formas corretas de dispor e tratar esses resíduos. Esses locais podem incluir também o Centro de Tratamento de Resíduos (CTR) de Barra Mansa, a COOPCAT (Cooperativa de Catadores de Resíduos de Barra Mansa) e o antigo "lixão" da cidade, para visitação e realização de aulas de campo.

Acredita-se que estas formas de interação com o objeto de estudo reforcem o processo de absorção e compreensão dos assuntos trabalhados, bem como estimulem a curiosidade e o desejo de participação mais ativa por parte dos alunos, o que pode ser um poderoso estímulo a mudanças de postura e atitude frente às questões ambientais, como atestou Costa (2011).

Posteriormente, o próximo passo será a utilização de um jogo educativo criado especialmente para este fim. A proposta desse estudo consiste em uma adaptação do jogo "Super-Trunfo", distribuído no Brasil pela companhia "Grow" (Figura1).

Figura 1 - foto ilustrativa do jogo original

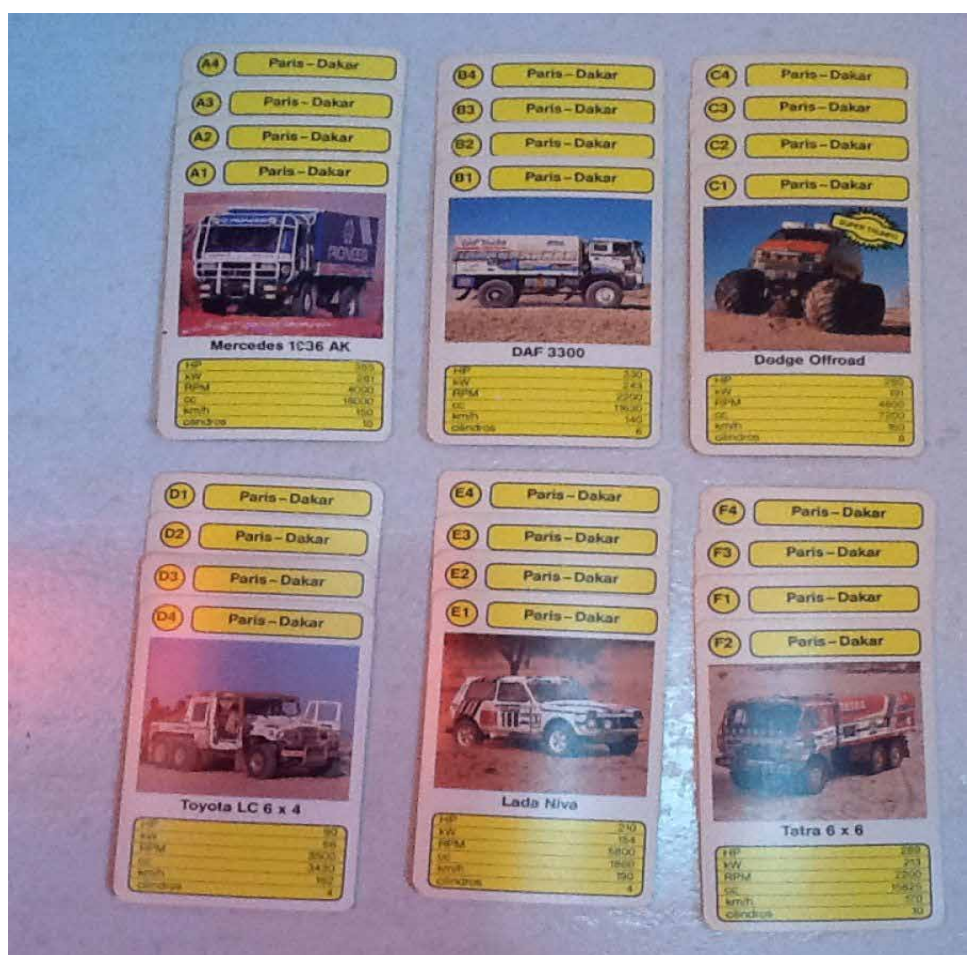

Fonte: Site Mercado Livre

Segundo Falkembach (2016), este tipo de jogo educativo estimula capacidade de raciocínio, memória e estratégia. A adaptação do jogo propõe informar os efeitos dos resíduos sólidos descartadas inadequadamente, além de levar os estudantes a conhecerem mais a fundo as características de diversos materiais que compõem o "lixo doméstico" e de perceberem os efeitos que eles mesmos podem causar pelo descarte desses materiais em locais inadequados. Por meio do jogo, eles poderão aprender, de forma espontânea e prazerosa, um conhecimento importante para sua postura enquanto cidadãos geradores de resíduos.

A elaboração e construção do jogo foram concluídas e encontra-se em andamento a aplicação e avaliação do produto. 


\section{DESENVOLVIMENTO EXPERIMENTAL}

O jogo se processa da seguinte forma: cada aluno recebe algumas cartas, nas quais existe uma foto ilustrativa, apresentando algum material ou objeto comumente encontrado no lixo doméstico comum, como por exemplo, latas de aço e alumínio, cascas de fruta, embalagens de vidro, plástico, borracha e materiais orgânicos. Abaixo da imagem, há quatro informações referentes ao material representado. São: o tempo (em meses e anos) para ser decomposto ou biodegradado quando abandonado na natureza; o risco de contaminação (que variou de um [menor risco] a três asteriscos [maior risco]); a origem do material (se orgânico ou inorgânico); e o tratamento adequado para este tipo específico de resíduo (Figura 2).

Figura 2 - Cartas do Jogo Educativo (inspirado e adaptado do jogo original "Super Trunfo")
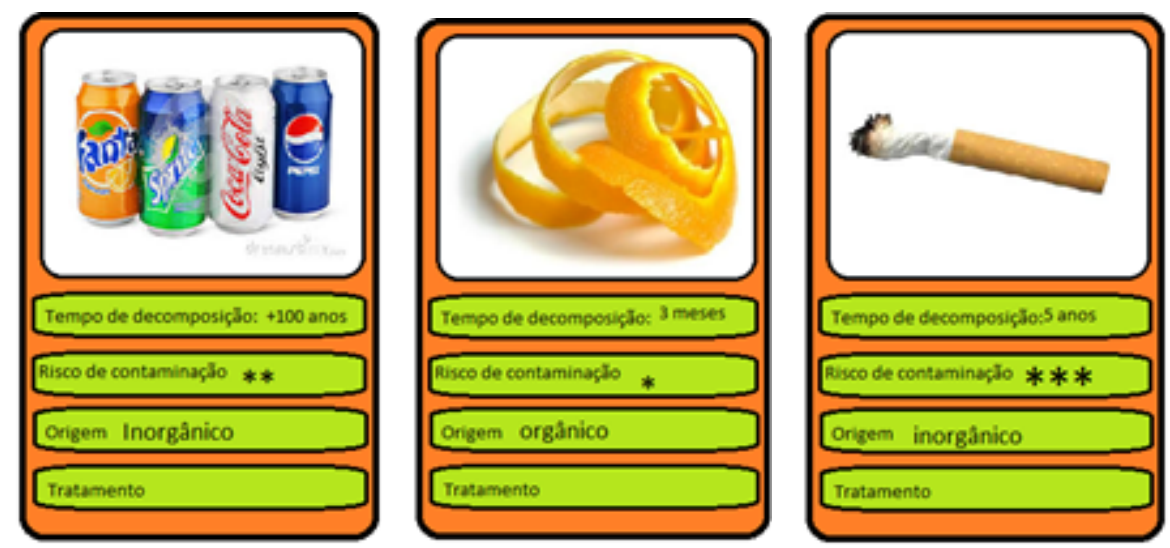

Fonte: Autores

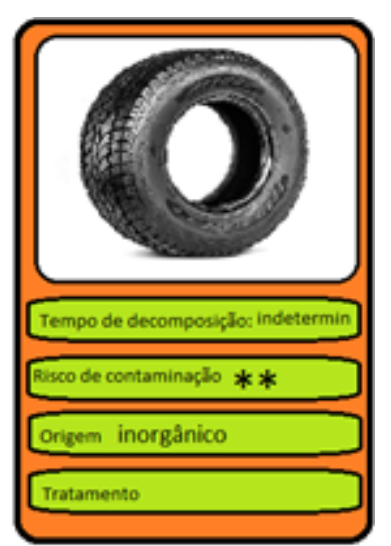

Um "aluno-jogador" escolhe uma de suas cartas e seleciona uma característica, como por exemplo, "tempo de decomposição", sendo que nenhum de seus colegas sabe qual carta ele escolheu. Todos colocam na mesa suas cartas e verificam os dados de cada uma. Aquela que tiver o resíduo com o menor tempo de decomposição é a carta vencedora, por ser o resíduo ecologicamente menos impactante ao ambiente. Eles continuam a proceder assim, sempre vencendo aquele cuja carta possui as características mais desejáveis, no tocante ao seu menor nível de impacto negativo sobre o ambiente. $O$ vencedor será aquele que tiver reunido, ao final do tempo da partida, todas as cartas, ou o maior número delas, comparado aos outros jogadores.

\section{RESULTADOS ESPERADOS E DISCUSSÃO}

Com a aplicação de jogos educativos dessa natureza, que abordam temas como biodiversidade e conservação, resíduos sólidos, degradação ambiental e tratamento adequado destes resíduos, temse uma ferramenta a mais para se compreender a importância do destino e tratamento apropriado dos resíduos para a preservação dos ecossistemas e dos recursos naturais.

A utilização de recursos lúdicos, como mostrado na produção e aplicação do jogo educativo aqui apresentado, teve a intenção de reafirmar os conceitos aprendidos e sanar as dúvidas existentes quanto ao assunto. A ludicidade busca novas formas de assimilação, incentivando a criatividade e a interação entre os alunos e professor. 


\section{CONCLUSÃO}

$\mathrm{Na}$ educação estreitam-se as relações entre transmissão de conhecimento e interação professor-aluno (CAMPOS et. al, 2003). Diante disso, o professor, durante o processo de aprendizagem, deve garantir a incorporação das percepções e interpretações individuais, das informações e conhecimentos do mundo dos alunos, interferir nos pensamentos, nas ações e atitudes, para, no fim, tornar útil o conhecimento adquirido, como visto em Campos (2003). Para que isso ocorra, o professor necessita direcionar métodos eficazes de ensino, com o objetivo de formar um elo entre o aluno e o conhecimento. Professor e aluno devem estar interligados em diferentes possibilidades interativas, para que os objetivos traçados sejam alcançados por ambas as partes (COSTA, 2011). Tendo em vista essas preocupações, torna-se necessário promover práticas em sala de aula, para promover um aprendizado significativo dos alunos (CAMPOS et. al, 2003). Diante disso, reforça-se que, além da aula expositiva tradicional, haja também outros recursos didáticos como os visuais, a utilização de jogos e demais obras interativas, para estabelecer uma situação adequada dentro de um processo de construção do conhecimento.

\section{REFERÊNCIAS}

AMORIM, Aline Pinto; JARDIM, Daniele Barros; ALBUQUERQUE, Beatriz Mello; GAUTÉRIO, Daiane Teixeira; MORRONE, Eduardo Corrêa; SOUZA, Rejane Magano. LIXÃO MUNICIPAL: abordagem de uma problemática ambiental na cidade do Rio Grande RS. Ambiente \& Educação (FURG), v. 15, p. 159-178, 2010.

ARAÚJO, Maria Christina B.; COSTA, Mônica Ferreira. Lixo no ambiente marinho. Ciência Hoje, v. 32, n. 191, 2003.

CAMPOS, L. M. Lunardi; FELICIO, A. K. C.; BORTOLOTTO, T. M. A produção de jogos didáticos para o ensino de Ciências e Biologia: uma proposta para favorecer a aprendizagem. Caderno dos Núcleos de Ensino, 2003 (em andamento), p. 35-48, 2003.

COSTA, Mariana da Cunha Canova. Freinet: Suas Contribuições ao processo de Sensibilização Ambiental, em especial a "Aula das Descobertas". Dissertação (Mestrado) - Programa de Pós Graduação do Setor de Educação. Universidade Federal do Paraná. 2011.

FALKEMBACH, Gilse A. M. O lúdico e os jogos Educacionais. Universidade Federal do Rio Grande do Sul, UFRGS, Centro Interdisciplinar de Novas Tecnologias na Educação. Disponível em: <http://penta3. ufrgs/midiasedu.modulo13/etapa1/leituras/arquivo/leitura.1pdf $\geq$. Acesso em: 10 mar. 2016.

GOMES, R. R.; FRIEDRICH,M. A Contribuição dos jogos didáticos no aprendizado de conteúdos de Ciências e Biologia. In: EREBIO,!, Rio de Janeiro, 2001, Anais... Rio de Janeiro, 2001, p. 389-392.

MORAES, Caroline LinkeAvaliação do passivo ambiental lixão desativado do município de Lages-SC / Caroline Linke Moraes. - Lages, 2014.

PANÇARDES, L. R. Central de Tratamento de Resíduoséinaugurada. Avozdacidade. BarraMansa, 20abr. 2012. Cidades, p.5.

PLANETA TERRA. Chorume. Disponível em: <http://planetaterranet.blogspot.com.br/2009/11/chorume.html> Acesso em: 21 maio 2015.

SILVA, Carlos Henrique R.T. Recursos Hídricos e Desenvolvimento Sustentável no Brasil. Disponível em: <http:// www12senai.gov.br/publicaçoes/estudos-legislstivo/tipos-de-estudos/outraspublicações/temas-e-eagendas-para-odesenvolvimento-sustentavel/recursos-hídricos-e-desenvolvimento-sustentavel-no-brasil $>$. Acesso em: 10 mar. 2016. 